\title{
Olfactory sulcus morphology in established bipolar affective disorder
}

Tsutomu Takahashi ${ }^{\mathrm{a},{ }^{*}, \text { Gin S. Malhi }}{ }^{\mathrm{c}, \mathrm{d}}$, Yumiko Nakamura ${ }^{\mathrm{a}}$, Michio

Suzuki $^{\mathrm{a}}$, Christos Pantelis ${ }^{\mathrm{b}}$

${ }^{a}$ Departments of Neuropsychiatry, University of Toyama, Toyama, Japan

${ }^{b}$ Melbourne Neuropsychiatry Centre, Department of Psychiatry, University of

Melbourne and Melbourne Health, Victoria, Australia

${ }^{c}$ Discipline of Psychological Medicine, Northern Clinical School, University of Sydney, Sydney, Australia

${ }^{d}$ CADE Clinic, Department of Psychiatry, Royal North Shore Hospital, Sydney, Australia

*Corresponding author: Tsutomu Takahashi, M.D.

Department of Neuropsychiatry, University of Toyama

2630 Sugitani, Toyama 930-0194, Japan

Tel.: +81-76-434-2281

Fax: +81-76-434-5030

E-mail: tsutomu@med.u-toyama.ac.jp 


\begin{abstract}
This MRI study examined the morphology of the olfactory sulcus, a potential marker of early neurodevelopment in 26 patients with bipolar I disorder and 24 matched controls. Bipolar patients had significantly shallower olfactory sulci bilaterally compared to controls, suggesting that neurodevelopmental abnormalities contribute to the neurobiology of bipolar disorder.
\end{abstract}

Key words: Bipolar disorder; Magnetic resonance imaging; Neurodevelopment. 


\section{Introduction}

A large number of studies suggest a close relationship between olfactory and affective information processing, with common underlying neural substrates including limbic structures (Soudry et al., 2011). Although olfactory function in bipolar disorder (BD) has not been well documented (Burón and Bulbena, 2013), several recent studies have demonstrated olfactory dysfunction in BD (Cumming et al., 2011; Hardy et al., 2012; Lahera et al., in press) or in a BD subgroup with psychotic symptoms (Striebel et al., 1999).

The olfactory sulcus appears during fetal development at around 16 weeks of gestation (Chi et al., 1977), and its depth has been related to olfactory function in healthy subjects (Hummel et al., 2003). For psychiatric disorders, an abnormally shallow olfactory sulcus has been reported in schizophrenia (Turetsky et al., 2009a; Takahashi et al., 2013), supporting the notion that olfactory dysfunction is a prominent feature of schizophrenia and may represent a marker of early neurodevelopmental abnormalities (Brewer et al., 2001; Turetsky et al., 2009b; Kamath et al., in press). In addition to clinical and biological commonality between BD and schizophrenia (Whalley et al., 2012; Tamminga et al., 2013), some neuroimaging (e.g., Takahashi et al., 2010) and post-mortem studies suggest a possible embryonic developmental etiology also in BD (reviewed by Sanches et al., 2008). Furthermore, BD patients and their unaffected first-degree relatives are likely to share brain morphologic changes related to olfactory processing (e.g., anterior-limbic structures) (Matsuo et al., 2012; Nery et al., 2013), suggesting that abnormalities in the olfactory structures may be at least partly associated with vulnerability to BD. It remains largely unknown, however, whether BD patients exhibit morphologic changes of the olfactory sulcus.

This magnetic resonance imaging (MRI) study investigated the olfactory sulcus morphology in BD patients and matched controls. Based on previous olfactory ability findings in $\mathrm{BD}$ and the potential role of olfactory sulcus depth as a marker of early neurodevelopment, we predicted a shallower olfactory sulcus in BD patients compared with controls. We also investigated the association between olfactory sulcus morphology and clinical features of BD. 


\section{Methods}

\subsection{Participants}

Twenty-six patients with DSM-IV bipolar I disorder and 24 age- and gender-matched healthy controls participated in this study (Table 1). Patients were recruited through advertisement and via a dedicated specialist bipolar disorder clinic based in Sydney, Australia. Diagnoses were made by a research psychiatrist (GM) using the Structured Clinical Interview for DSM-IV (SCID-IV-P) (First et al., 1998), supplemented by case note review. The majority of patients were euthymic at the time of scanning. Controls were recruited predominantly via advertisement, and they were screened for a personal and family history of psychiatric or neurological disorder using the SCID-IV nonpatient version (SCID-NP). Participants were right-handed and excluded if they had a history of ongoing substance misuse, neurological disease or, in patients, if there was a co-morbid Axis I or II DSM-IV diagnosis that required treatment. All participants gave written informed consent and the local Hospital and University ethics committee approved the study.

At the time of scanning, eight patients were taking lithium, seven were taking valproate, and four were taking a combination of both. One patient was taking valproate and carbamazepine, and another was taking carbamazepine alone, while five patients were medication free. All patients had previously been exposed to antipsychotic medication, although none within 12 months of entering the study. Ten patients had a family history of major affective disorders (bipolar disorder, $N=3$; unipolar depression, $N=5$; and both, $N=2$ ), while 12 had no family history of affective disorders and four had an unknown family history. Sixteen patients had a history of psychosis (hallucinations and/or delusions) during at least one affective episode.

\subsection{MRI procedures}

T1-weighted MR scans were acquired with a 1.5-T GE Signa scanner. Imaging parameters were as follows: echo time, $5.3 \mathrm{~ms}$; repetition time, $12.2 \mathrm{~ms}$; field of view, $24.9 \mathrm{~cm}$; voxel dimensions, $0.98 \times 0.98 \times 1.6 \mathrm{~mm}$ thick coronal slices. The intracranial volume (ICV) was measured as previously described (Eritaia et al., 2000); the groups did not differ in their ICVs (Table 1). 
For the assessment of the olfactory sulcus, the images were processed on a Linux PC using Dr. View software (AJS, Tokyo, Japan). Brain images were realigned in three dimensions and reconstructed into contiguous coronal images with a $0.98-\mathrm{mm}$ thickness, perpendicular to the anterior commissure-posterior commissure line. As described in detail elsewhere (Takahashi et al., 2013), one rater (TT), who was blind to the subjects' identity, measured the depth of the olfactory sulcus in all coronal slices where the sulcus was clearly seen. On each coronal slice, the olfactory sulcus was traced beginning with the deepest point of the sulcus and ending inferiorly with a tangent line connecting the top surfaces of the gyrus rectus and medial orbital gyrus (Rombaux et al., 2009) (eFig. 1). The length of the sulcus in the anterior-posterior direction $(\mathrm{mm})$ was determined by the multiplication of the number of these coronal slices by 0.98 . Intra- and inter-rater (TT and YN) intraclass correlation coefficients for the length and depth of the sulcus in 10 randomly selected brains were over 0.8 .

\subsection{Statistical analysis}

The average depth (sum of the depth in all slices containing the sulcus/slice number) and length of the olfactory sulcus were analyzed using repeated measures analysis of covariance (ANCOVA), with age and ICV as covariates, diagnosis and gender as between-subject factors, and hemisphere as a within-subject variable. The sulcus morphology of the patient subgroups (psychotic and nonpsychotic, with and without a family history, with and without lithium or valproate treatment at scanning) was also analyzed by ANCOVA, covarying for age and ICV. Post-hoc Scheffé's tests were used.

The relationships between the olfactory sulcus measures and clinical variables were examined using Pearson's partial correlation coefficients controlling for age and ICV. The number of manic/depressive episodes was log-transformed because of their skewed distribution. Statistical significance was defined as $P<0.05$. 


\section{Results}

ANCOVA of the sulcus depth revealed significant main effects for diagnosis $[F(1$, $44)=51.55, P<0.001]$ and hemisphere $[F(1,46)=83.14, P<0.001]$ but no interaction between these factors; the BD patients had a shallower sulcus than controls, and the sulcus was deeper in the right than in the left hemisphere (Table 1, eFig. 2). There was no group difference in the sulcus length, but the olfactory sulcus was longer in the right hemisphere $[F(1,46)=6.88, P=0.012]$ (Table 1$)$. No significant effect involving gender was found.

There were no significant differences in the sulcus measures between the patient subgroups on the basis of psychotic symptoms, family history, and lithium treatment status. The BD patients taking valproate had a longer sulcus bilaterally compared with those who were not on valproate treatment $[F(1,22)=7.73, P=0.011]$.

No significant relation was found between the olfactory sulcus measures and clinical variables in the BD patients (onset age, illness duration, number of manic/depressive episodes, dosage of lithium or valproate) after Bonferroni correction. Age, IQ, and education did not significantly correlate with the sulcus measures in either group.

\section{Discussion}

To our knowledge, this is the first MRI study to report the morphologic changes of the olfactory sulcus in established bipolar I disorder. The BD patients had significantly shallower olfactory sulci bilaterally compared with controls, but there was no group difference in its anterior-posterior length. Illness duration, number of affective episodes, and medication status did not affect the sulcus depth of the patients, suggesting that it might be a static illness marker reflecting abnormal neurodevelopment.

Olfactory dysfunction appears to be a promising vulnerability marker of schizophrenia (e.g., Turetsky et al., 2009b), and early studies have reported relatively intact olfactory function in BD (Burón and Bulbena, 2013). However, several recent studies have demonstrated olfactory impairment in BD and a relationship to their affective (Cumming et al., 2011; Hardy et al., 2012) or psychotic (Striebel et al., 1999) 
symptomatology as well as social functioning (Hardy et al., 2012; Lahera et al., in press), which could be partly attributable to a close functional and neuroanatomical relationship between olfactory ability, emotional processing, and social cognition (Soudry et al., 2011; Lahera et al., in press). The present MRI results of abnormally shallow olfactory sulcus in BD partly support these olfactory ability findings, as this anatomical abnormality could be associated with embryonic disruption of olfactory system development (Abolmaali et al., 2002; Hummel et al., 2003). However, rather intact olfactory functioning before illness onset and its deficits in first-episode psychotic BD (Brewer et al., 2001, 2003) raise the possibility that progressive changes in olfactory functioning may occur following illness onset. Although our findings suggest a role of neurodevelopmental abnormalities in the neurobiology of BD, future longitudinal studies should examine whether the olfactory sulcus morphology remains stable in the course of BD.

Regarding the timing of neurodevelopmental abnormalities in BD, we previously demonstrated abnormally small adhesio interthalamica (Takahashi et al., 2010), which develops at a similar gestation period as the olfactory sulcus (Rosales et al., 1968), in the same BD subjects as in this study. However, these patients had normal size of the cavum septi pellucidi (Takahashi et al., 2010), which is related to fusion of the septum pellucidi within 3-6 months of birth (Shaw and Alvord, 1969), supporting the idea that $\mathrm{BD}$ is more closely related to aberrant neurodevelopment early in gestation.

We did not assess olfactory function or additional olfactory structures (e.g., olfactory bulb), representing a limitation of the study. Furthermore, the small sample number and heterogeneity (e.g., history of psychosis, family history of affective disorders, medication status, and number of episodes) of BD patients limited our ability to generalize the findings. Mood stabilizers may affect brain morphology (Moore et al., 2000) as well as olfactory discrimination ability (Castro et al., 2012), but comprehensive medication data (e.g., lifetime medication) were not available. Given our unexpected finding of the effect of valproate on the sulcus length, possible effects of medication as well as other possible confounding factors on olfactory sulcus morphology are worthy of further examination in larger and well-characterized BD cohorts. As olfactory deficits are also reported in other psychiatric disorders such as major depression (Burón and Bulbena, 2013), the disease specificity of our findings should be further examined. 


\section{Acknowledgements}

This research was supported in part by Grants-in-Aid for Scientific Research (C) (No. 22591275, 24591699) and Grants-in-Aid for Scientific Research (B) (No. 24390281) from the Japanese Society for the Promotion of Science, Health and Labour Sciences Research Grants (Comprehensive Research on Disability, Health and Welfare, H23-Seishin-Ippan-002 and H23-Seishin-Ippan-009), a Grant from Research Group For Schizophrenia, Japan, and a Research Grant from the JSPS Asian Core Program. Prof. Christos Pantelis was supported by a NHMRC Senior Principal Research Fellowship (ID: 628386), NARSAD Distinguished Investigator Award. 


\section{References}

Abolmaali, N.D., Hietschold, V., Vogl, T.J., Hüttenbrink, K.B., Hummel, T., 2002. MR evaluation in patients with isolated anosmia since birth or early childhood. American Journal of Neuroradiology 23, 157-164.

Brewer, W.J., Pantelis, C., Anderson, V., Velakoulis, D., Singh, B., Copolov, D.L., McGorry, P.D., 2001. Stability of olfactory identification deficits in neuroleptic-naive patients with first-episode psychosis. American Journal of Psychiatry 158, 107-115.

Brewer, W.J., Wood, S.J., McGorry, P.D., Francey, S.M., Phillips, L.J., Yung, A.R., Anderson, V., Copolov, D.L., Singh, B., Velakoulis, D., Pantelis, C., 2003. Impairment of olfactory identification ability in individuals at ultra-high risk for psychosis who later develop schizophrenia. American Journal of Psychiatry 160, 1790-1794.

Burón, E., Bulbena, A., 2013. Olfaction in affective and anxiety disorders: a review of the literature. Psychopathology 46, 63-74.

Castro, A.A., Ghisoni, K., Latini, A., Quevedo, J., Tasca, C.I., Prediger, R.D., 2012. Lithium and valproate prevent olfactory discrimination and short-term memory impairments in the intranasal 1-methyl-4-phenyl-1,2,3,6-tetrahydropyridine (MPTP) rat model of Parkinson's disease. Behavioural Brain Research 229, 208-215.

Chi, J.G., Dooling, E.C., Gilles, F.H., 1977. Gyral development of the human brain. Annals of Neurology 1, 86-93.

Cumming, A.G., Matthews, N.L., Park, S., 2011. Olfactory identification and preference in bipolar disorder and schizophrenia. European Archives of Psychiatry and Clinical Neurosciences 261, 251-259.

Eritaia, J., Wood, S.J., Stuart, G.W., Bridle, N., Dudgeon, P., Maruff, P., Velakoulis, D., Pantelis, C., 2000. An optimized method for estimating intracranial volume from magnetic resonance images. Magnetic Resonance in Medicine 44, 973-977.

First, M.B., Spitzer, R.L., Gibbon, M., Williams, J.B.W., 1998. Structured Clinical Interview for DSM-IV. American Psychiatric Press, Washington, DC. 
Hardy, C., Rosedale, M., Messinger, J.W., Kleinhaus, K., Aujero, N., Silva, H., Goetz, R.R., Goetz, D., Harkavy-Friedman, J., Malaspina, D., 2012. Olfactory acuity is associated with mood and function in a pilot study of stable bipolar disorder patients. Bipolar Disorders 14, 109-117.

Hummel, T., Damm, M., Vent, J., Schmidt, M., Theissen, P., Larsson, M., Klussmann, J.P., 2003. Depth of olfactory sulcus and olfactory function. Brain Research 975, 85-89.

Kamath, V., Turetsky, B.I., Calkins, M.E., Kohler, C.G., Conroy, C.G., Borgmann-Winter, K., Gatto, D.E., Gur, R.E., Moberg, P.J. Olfactory processing in schizophrenia, non-ill first-degree family members, and young people at-risk for psychosis. World Journal of Biological Psychiatry, in press.

[doi:10.3109/15622975.2011.615862]

Lahera, G., Ruiz-Murugarren, S., Fernández-Liria, A., Saiz-Ruiz, J., Buck, B.E., Penn, D.L. Relationship between olfactory function and social cognition in euthymic bipolar patients. CNS Spectrums, in press. [DOI: 10.1017/S1092852913000382]

Matsuo, K., Kopecek, M., Nicoletti, M.A., Hatch, J.P., Watanabe, Y., Nery, F.G., Zunta-Soares, G., Soares, J.C., 2012. New structural brain imaging endophenotype in bipolar disorder. Molecular Psychiatry 17, 412-420.

Moore, G.J., Bebchuk, J.M., Wilds, I.B., Chen, G., Manji, H.K., 2002. Lithium-induced increase in human brain grey matter. Lancet 356, 1241-1242.

Nery, F.G., Monkul, E.S., Lafer, B., 2013. Gray matter abnormalities as brain structural vulnerability factors for bipolar disorder: A review of neuroimaging studies of individuals at high genetic risk for bipolar disorder. Australian and New Zealand Journal of Psychiatry 47, 1124-1135.

Rombaux, P., Grandin, C., Duprez, T., 2009. How to measure olfactory bulb volume and olfactory sulcus depth? B-ENT 5 Suppl 13, 53-60.

Rosales, R.K., Lemay, M.J., Yakovley, P.I., 1968. The development and involution of massa intermedia with regard to age and sex. Journal of Neuropathology and Experimental Neurology 27, 166.

Sanches, M., Keshavan, M.S., Brambilla, P., Soares, J.C., 2008. Neurodevelopmental basis of bipolar disorder: a critical appraisal. Progress in Neuro-Psychopharmacology and Biological Psychiatry 32, 1617-1627 
Shaw, C.M., Alvord, E.C. Jr., 1969. Cava septi pellucidi et vergae: their normal and pathogical states. Brain 92, 213-223.

Soudry, Y., Lemogne, C., Malinvaud, D., Consoli, S.M., Bonfils, P., 2011. Olfactory system and emotion: common substrates. European Annals of Otorhinolaryngology, Head and Neck Diseases 128, 18-23.

Striebel, K.M., Beyerstein, B., Remick, R.A., Kopala, L., Honer, W.G., 1999. Olfactory identification and psychosis. Biological Psychiatry 45, 1419-1425.

Takahashi, T., Malhi, G.S., Wood, S.J., Yücel, M., Walterfang, M., Nakamura, K., Suzuki, M., Pantelis, C., 2010. Midline brain abnormalities in established bipolar affective disorder. Journal of Affective Disorders 122, 301-305.

Takahashi, T., Nakamura, Y., Nakamura, K., Ikeda, E., Furuichi, A., Kido, M., Kawasaki, Y., Noguchi, K., Seto, H., Suzuki, M., 2013. Altered depth of the olfactory sulcus in first-episode schizophrenia. Progress in Neuro-Psychopharmacology and Biological Psychiatry 40, 167-172.

Tamminga, C.A., Ivleva, E.I., Keshavan, M.S., Pearlson, G.D., Clementz, B.A., Witte, B., Morris, D.W., Bishop, J., Thaker, G.K., Sweeney, J.A., 2013. Clinical Phenotypes of Psychosis in the Bipolar and Schizophrenia Network on Intermediate Phenotypes (B-SNIP). American Journal of Psychiatry 170, 1263-1274.

Turetsky, B.I., Crutchley, P., Walker, J., Gur, R.E., Moberg, P.J., 2009a. Depth of the olfactory sulcus: a marker of early embryonic disruption in schizophrenia?

Schizophrenia Research 115, 8-11.

Turetsky, B.I., Hahn, C.G., Borgmann-Winter, K., Moberg, P.J., 2009b. Scents and nonsense: olfactory dysfunction in schizophrenia. Schizophrenia Bulletin 35, $1117-1131$.

Whalley, H.C., Papmeyer, M., Sprooten, E., Lawrie, S.M., Sussmann, J.E., McIntosh, A.M., 2012. Review of functional magnetic resonance imaging studies comparing bipolar disorder and schizophrenia. Bipolar Disorders 14, 411-431. 
Figure Legends (for electronic supplementary materials)

eFig. 1. T1 coronal image of the olfactory sulcus at the level of PPTE (posterior tangent through the eyeballs).

eFig. 2. Olfactory sulcus depth in the patients with bipolar disorder and healthy controls. Horizontal lines indicate mean values. Post hoc Scheffé's test: $* P<0.01$. 


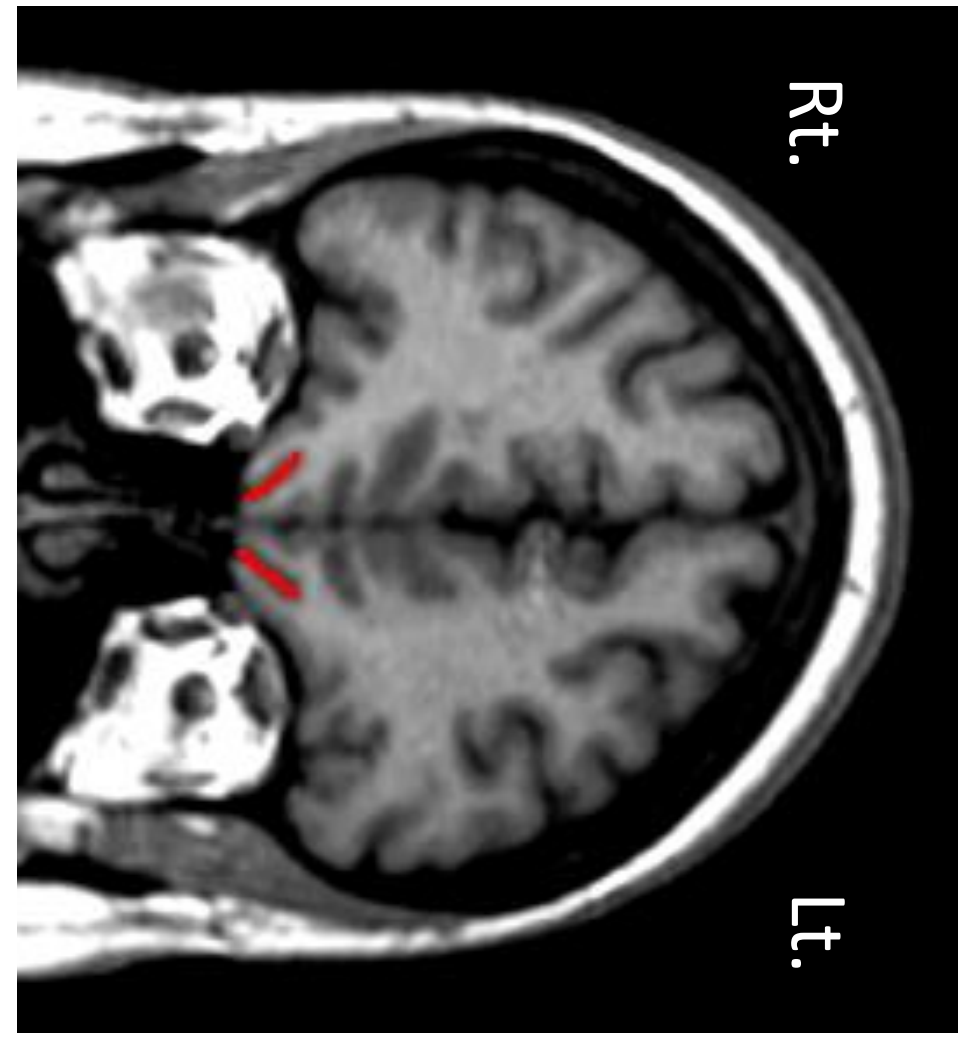


ํำ

Olfactory sulcus depth (mm)

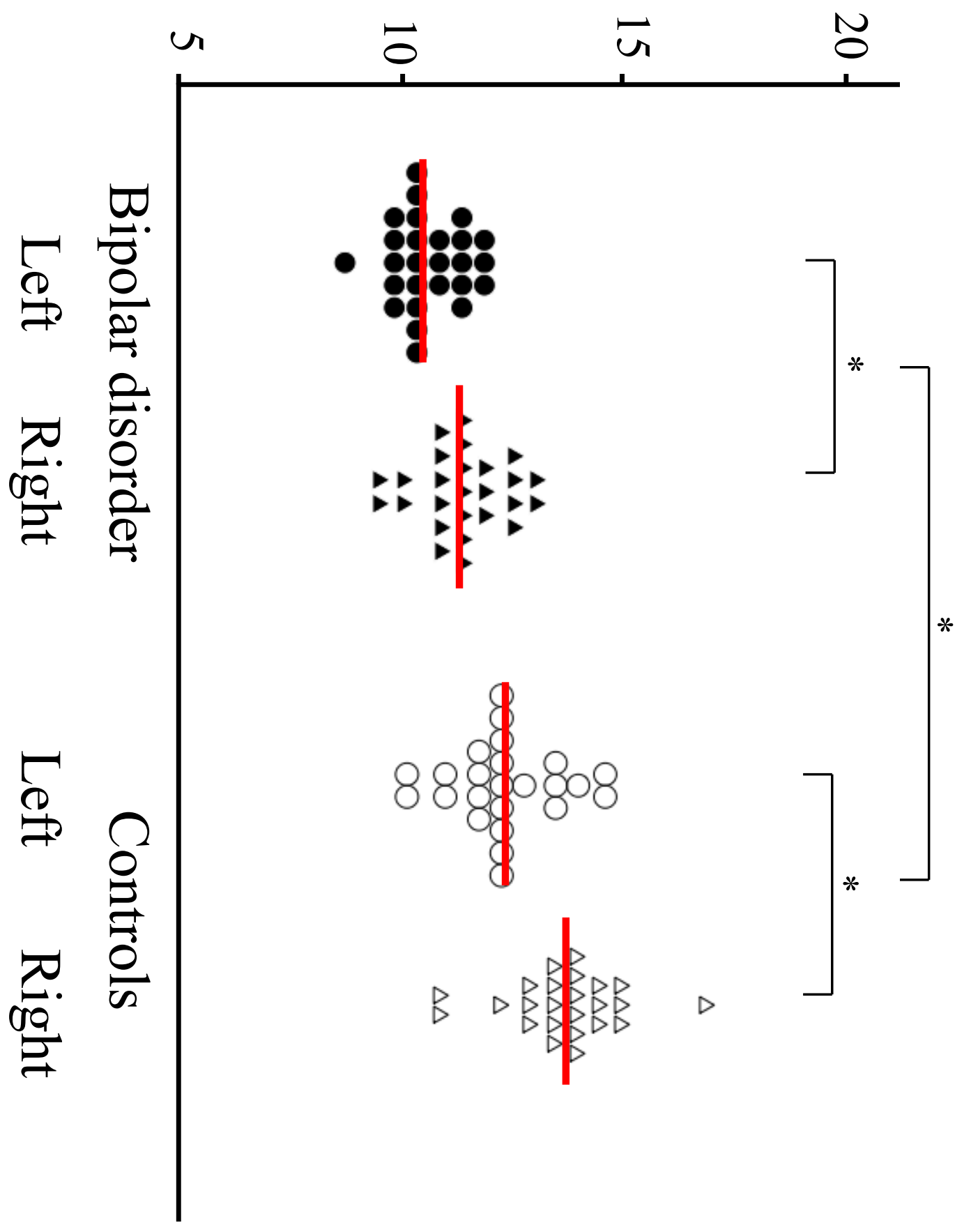


Table 1

Sample characteristics and olfactory sulcus measures.

\begin{tabular}{|c|c|c|c|c|c|c|c|}
\hline Variable & & $\begin{array}{l}\text { Healthy } \\
\text { controls } \\
(N=24)\end{array}$ & & & $\begin{array}{l}\text { Bipolar } \\
\text { patients } \\
(N=26)\end{array}$ & & Group comparison \\
\hline & 38. & & 11 & 38. & & 10 & ANOVA: $F(1,48)=0.01$ \\
\hline Age (years) & 7 & \pm & .1 & 4 & \pm & .9 & $P=0.928$ \\
\hline Male/female & & $7 / 17$ & & & $8 / 18$ & & $\begin{array}{l}\text { Chi-square }=0.02, P= \\
0.902\end{array}$ \\
\hline NART-estimated $\mathrm{IQ}^{\mathrm{a}}$ & $\begin{array}{r}115 \\
.1\end{array}$ & \pm & $\begin{array}{l}9 . \\
6\end{array}$ & $\begin{array}{r}113 \\
.8\end{array}$ & \pm & $\begin{array}{l}7 . \\
1\end{array}$ & $\begin{array}{l}\text { ANOVA: } F(1,47)=0.28 \\
P=0.597\end{array}$ \\
\hline Education (years) & $\begin{array}{r}14 . \\
6\end{array}$ & \pm & $\begin{array}{l}2 . \\
1\end{array}$ & $\begin{array}{r}14 . \\
7\end{array}$ & \pm & $\begin{array}{l}2 . \\
8\end{array}$ & $\begin{array}{l}\text { ANOVA: } F(1,48)=0.02 \\
P=0.899\end{array}$ \\
\hline Illness duration (years) & & - & & & \pm & .1 & - \\
\hline $\begin{array}{l}\text { Number of manic } \\
\text { episodes }\end{array}$ & & - & & 8.8 & \pm & $\begin{array}{l}10 \\
.2\end{array}$ & - \\
\hline $\begin{array}{l}\text { Number of depressive } \\
\text { episodes }\end{array}$ & & ( & & $\begin{array}{r}11 . \\
1\end{array}$ & \pm & $\begin{array}{l}10 \\
.8\end{array}$ & - \\
\hline $\begin{array}{l}\text { Lithium dosage (mg, } N \\
=12)\end{array}$ & & - & & 975 & \pm & $\begin{array}{l}21 \\
3\end{array}$ & - \\
\hline $\begin{array}{l}\text { Valproate dosage (mg, } \\
N=12 \text { ) }\end{array}$ & & - & & $\begin{array}{r}143 \\
7\end{array}$ & \pm & $\begin{array}{l}59 \\
4\end{array}$ & - \\
\hline $\begin{array}{l}\text { Intracranial volume } \\
\left(\mathrm{cm}^{3}\right)\end{array}$ & $\begin{array}{r}146 \\
1\end{array}$ & \pm & $\begin{array}{l}14 \\
8\end{array}$ & $\begin{array}{r}147 \\
6\end{array}$ & \pm & $\begin{array}{l}12 \\
6\end{array}$ & $\begin{array}{l}\text { ANCOVA }^{\mathrm{b}}: F(1,47)=0.13 \\
P=0.715\end{array}$ \\
\hline $\begin{array}{l}\text { Olfactory sulcus length } \\
(\mathrm{mm})\end{array}$ & & & & & & & $\begin{array}{l}\text { ANCOVA: } F(1,44)< \\
0.01, P=0.988\end{array}$ \\
\hline Left & $\begin{array}{r}43 . \\
9\end{array}$ & \pm & $\begin{array}{l}4 . \\
7\end{array}$ & $\begin{array}{r}44 . \\
1\end{array}$ & \pm & $\begin{array}{l}4 . \\
3\end{array}$ & \\
\hline Right & 44. & \pm & 4. & 45. & \pm & 3. & \\
\hline
\end{tabular}


$7 \quad 7^{\mathrm{c}} \quad 4 \quad 8^{\mathrm{c}}$

Olfactory sulcus depth

$(\mathrm{mm})$

ANCOVA: $F(1,44)=51.55$, $P<0.001$

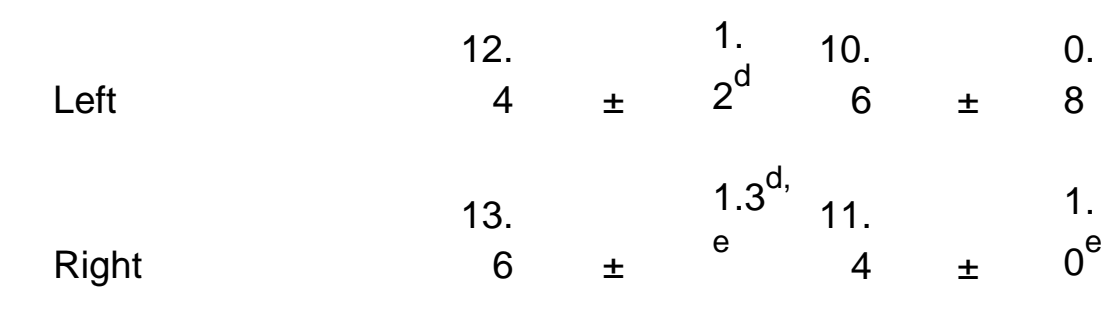

Data are presented as

mean \pm SD.

ANCOVA, analysis of covariance; ANOVA, analysis of variance; IQ, intelligence quotient; NART, National Adult Reading Test.

a Data missing for one

bipolar patient.

${ }^{\mathrm{b}}$ Age was used as a

covariate.

${ }^{\mathrm{c}} P=0.007$ : longer than in left hemisphere (post

hoc Scheffé's test ).

${ }^{d} P<0.001$ : deeper than in bipolar patients (post hoc Scheffé's test ).

e $P<0.001$ :deeper than in left hemisphere (post hoc Scheffé's test ). 


\section{University Library}

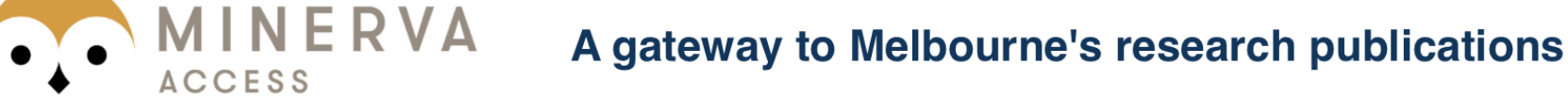

Minerva Access is the Institutional Repository of The University of Melbourne

Author/s:

Takahashi, T;Malhi, GS;Nakamura, Y;Suzuki, M;Pantelis, C

Title:

Olfactory sulcus morphology in established bipolar affective disorder

Date:

2014-04-30

Citation:

Takahashi, T., Malhi, G. S., Nakamura, Y., Suzuki, M. \& Pantelis, C. (2014).

Olfactory sulcus morphology in established bipolar affective disorder. PSYCHIATRY RESEARCH-NEUROIMAGING, 222 (1-2), pp.114-117. https://doi.org/10.1016/ j.pscychresns.2014.02.005.

Publication Status:

Accepted manuscript

Persistent Link:

http://hdl.handle.net/11343/41918 